E3S Web of Conferences 1, 39004 (2013)

DOI: $10.1051 / \mathrm{e} 3 \operatorname{sconf} / 20130139004$

(C) Owned by the authors, published by EDP Sciences, 2013

\title{
Chlorophyll fluorescence imaging of cadmium-treated white cabbage plants
}

\author{
M. Borek, R. Bączek-Kwinta and M. Rapacz
}

Department of Plant Physiology, Faculty of Agriculture and Economics, University of Agriculture, ul. Podłużna 3, 30239 Cracow, POLAND, borek.malgorzata@gmail.com,rrbaczek@cyf-kr.edu.pl

\begin{abstract}
The chlorophyll fluorescence imaging technique is a valuable tool to study the impact of heavy metal stress in plants. The aim of this paper was to investigate the influence of $\mathrm{Cd}$ on photosynthetic apparatus of white cabbage (Brassica oleracea subsp. capitata f. alba) plants. Two cabbage cultivars 'Ditmarska Najwcześniejsza' ('DN'; early) and 'Amager Polana' ('AP'; late) were used. Cd was applied before planting seedlings ( $10 \mathrm{mg} \mathrm{Cd} \mathrm{kg}^{-1} \mathrm{DM}$ of soil).. Measurements were performed at the $3 \mathrm{rd}$ leaf after 2 weeks of planting. The level of Cd-induced stress to plants was estimated by chlorophyll (Chl) content (photometrically) and analyses of images and numeric values of the major fluorescence parameters of $\mathrm{Chl}$ (Chl fluorescence imaging system FluorCam). Cd negatively affected the chlorophyll content and Fv/Fm, Fv'/Fm', $\phi$ PsII and qP in leaves of early cultivar of white cabbage. However, in the case of late cv. we did not observe such distinct changes. It suggests that late cultivars. are more resistant to $\mathrm{Cd}$ than the early ones. Considering methodological aspect of the study, Chl fluorescence imaging can better reveal some alterations within the leaf, because numeric values of specific parameters, which are the averaged data collected from the whole leaf, cannot reflect the tissue specificity.
\end{abstract}

Abbreviations: HM - heavy metal, Cd - cadmium, Chl - chlorophyll, Fv/Fm - photochemical efficiency of PSII in the dark-adapted state, F'v'/F'm' - PSII maximum efficiency, $\phi$ PSII - quantum efficiency of PSII electron transport, NPQ - nonphotochemical quenching of maximal Chl fluorescence, $\mathrm{qP}$ - photochemical quenching coefficient.

Key words: Chlorophyll fluorescence, imaging, photosynthetic apparatus, cadmium toxicity, phytoremediation, white cabbage.

\section{Introduction}

Cadmium is one of the most toxic heavy metals which occur in the environment as a result of industrial processes, intensive use of fertilizers in agriculture (Hsu and Kao, 2004), mining and also from the exhaust gases of automobiles (Das et al,. 1997). It can be easily uptaken and accumulated in plants leading to losses in agricultural yield and hazardous health effects as it enters the food chain (Hsu and Kao, 2004; Murakami et al., 2007). Phytoremediation of soils contaminated by $\mathrm{HM}$ is becoming more popular worldwide. There are several types of phytoremediation, which differ in the utilization of plants and a place where they are used. Phytoextraction is based on the use of plants that are able to accumulate large quantities of metals and produce high biomass (Wei et al,. 2008). The species belonging to botanical family Brassicaceae can fulfill these two main conditions.

Our earlier studies revealed the usefulness of white cabbage (Brassica oleracea subsp. capitata f. alba) for the purification of the soil from $\mathrm{Cd}$ by phytoextraction (Baczek-Kwinta et al., 2011a).

In recent years $\mathrm{Chl}$ fluorescence techniques has become irreplaceable in detection and evaluation of stress in plants (Lichtenthaler and Miehè, 1997; Roháček et al., 2008). They allow to perform highly accurate measurements without damaging the leaf. Moreover, they provide a lot of information about the actual state of photosynthetic apparatus of the leaf and also offer the possibility to screen gradients and irregularities of $\mathrm{Chl}$ fluorescence signatures over the whole leaf area (Lichtenthaler et al., 2000). 
The aim of this paper was to investigate the influence of $\mathrm{Cd}$ on the photosynthetic apparatus of white cabbage.

\section{Materials and Methods}

\section{Plant material and growth conditions}

Plants of white cabbage (Brassica oleracea subsp. capitata f. alba) cultivars: 'Ditmarska Najwcześniejsza' ('DN'; early) and 'Amager Polana' ('AP'; late) were produced from seeds in controlled conditions, in a phytotron of University of Agriculture in Cracow (day/night temperatures $16 / 12{ }^{\circ} \mathrm{C}, 14$-h photoperiod and relative humidity $60 \pm 5 \%$ ).

Seedlings at their stage of 6-8 leaves were transferred into the pots filled with the local soil (clay silt, 35\% silt and clay, $\mathrm{pH} 7,29)$. The concetration of $\mathrm{Cd}$ chosen for the present study was based on previous experiments (Antonkiewicz et al., 2006, BaczekKwinta et al., 2011a). Cd in the amount of $10 \mathrm{mg} \mathrm{Cd}$ $\mathrm{kg}^{-1} \mathrm{DM}$ of soil (in the form of $\mathrm{CdSO}_{4} \cdot 8 \mathrm{H}_{2} 0$ ) was added to the soil before planting seedlings. Control pots were the ones with the same soil, but without adding of Cd.

Plants were grown for 2 weeks with temperature of $25-20{ }^{\circ} \mathrm{C}$ day/ $20-17{ }^{\circ} \mathrm{C}$ night and $30 \%$ ralative humidity.

\section{Measurements and analyses}

Measurments were performed at 3rd leaf counting from the top of the plant. The level of Cd-induced stress to plants was estimated by the Chl content measured photometrically with SPAD chlorophyllmeter (Konica Minolta, Japan) and analyses of the major fluorescence parameters of Chl (Chlorophyll fluorescence imaging system FluorCam 701 MF, PSI, Brno, Czech Republic) revealing photosystem II (PSII) activity.

\section{Statistical analysis:}

The differences within the stage and the cultivar were estimated using the Student's t-test.

\section{Results and Discussion}

\section{Effect of Cd on chlorophyll content}

The amount of Chl was decreased in leaves of early cultivar ('DN') under the influence of $\mathrm{Cd}$ (Fig. 1.). However, in the case of late cv. ('AP'), there was no statistically significant differences in chlorophyll content. It suggests that early cultivars are more sensitive to $\mathrm{Cd}$ than the late ones.

The negative effect of $\mathrm{Cd}$ on pigment content in leaves has been described by several workers on various crops. Chen et al. (2011) reported that chlorophyll $a$, chlorophyll $b$ and total chlorophyll content were limited by $\mathrm{Cd}$ toxicity in pakchoi and mustard leaves. Similar results were obtained by Haouari et al. (2012) on tomato and Shafi Tantrey and Agnihotri (2010) on gram. The toxic effect of $\mathrm{Cd}$ on pigment content in leaves was dependent on its concentration.

\section{Effect of Cd on Chl fluorescence parameters}

Images of $\mathrm{Fv} / \mathrm{Fm}, \mathrm{Fv}^{\prime} / \mathrm{Fm}^{\prime}, \phi$ PSII, NPQ and $\mathrm{qP}$ are shown in Fig. 2. These images illustrate the differences in photosynthetic characteristic between control and Cdtreated white cabbage plants.

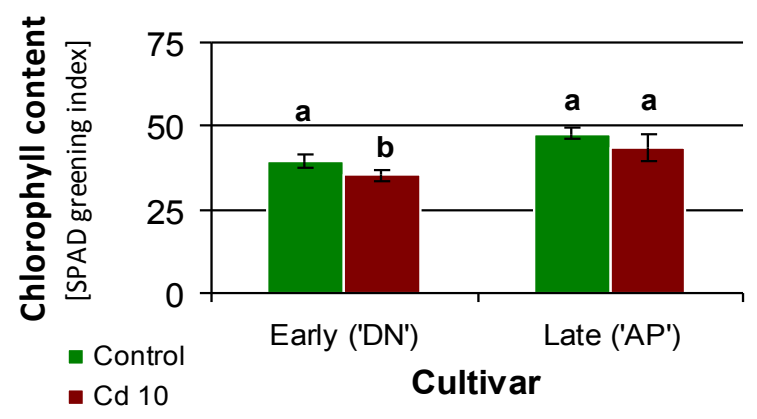

Fig. 1. The effect of $\mathrm{Cd}$ on chlorophyll content in leaves of white cabbage plants. Mean \pm SD. The means labelled with the same letter are not significantly differentiated ( $n=4 ; \mathrm{P}<0.01$; paired Student's $t$-test).

In case of early cv., they reveal more areas of lowered activity in Cd-treated plants comparing to control ones (Fig. 2A). Also the averaged values of Fv/Fm, Fv'/Fm', $\phi$ PSII and qP decreased. However, NPQ seemed to be higher when analyzing the image (Fig. 2A), but averaged values remained unchanged (Tab. 1.). The decrease in $\mathrm{Fv} / \mathrm{Fm}$ suggests diminished photochemical capacity of PSII while Fv'/Fm' gives an important information about PSII maximum efficiency (BączekKwinta et al., 2011b). $\phi$ PSII and qP can be interrelated with Fv/Fm (Maxwell and Johnson, 2000). The changes in values of these all parameters may be associated with alterations in chlorophyll content which were described in earlier paragraph (Fig. 1) and suggest that $\mathrm{Cd}$ caused PSII activity inhibition. NPQ alterations imply that the nonphotochemical quenching of maximal $\mathrm{Chl}$ fluorescence was increased by $\mathrm{Cd}$ treatment allowing to dissipate the excessive energy within the photosystems (Maxwell and Johnson 2000, Sofo et al., 2009).

In the case of late cultivar, the images of $\mathrm{Chl}$ fluorescence, did not show such discrepancies between control and Cd-treated plants (Fig. 2B), although control leaves revealed more sections of higher Fv'/Fm', $\phi_{\text {PSII }}$ and NPQ than control ones. .No changes in values of fluorescence parameters were noticed ( $\mathrm{Tab}$ 1.). It suggests that late cultivar is more resistant to $\mathrm{Cd}$ treatment than the early one. 

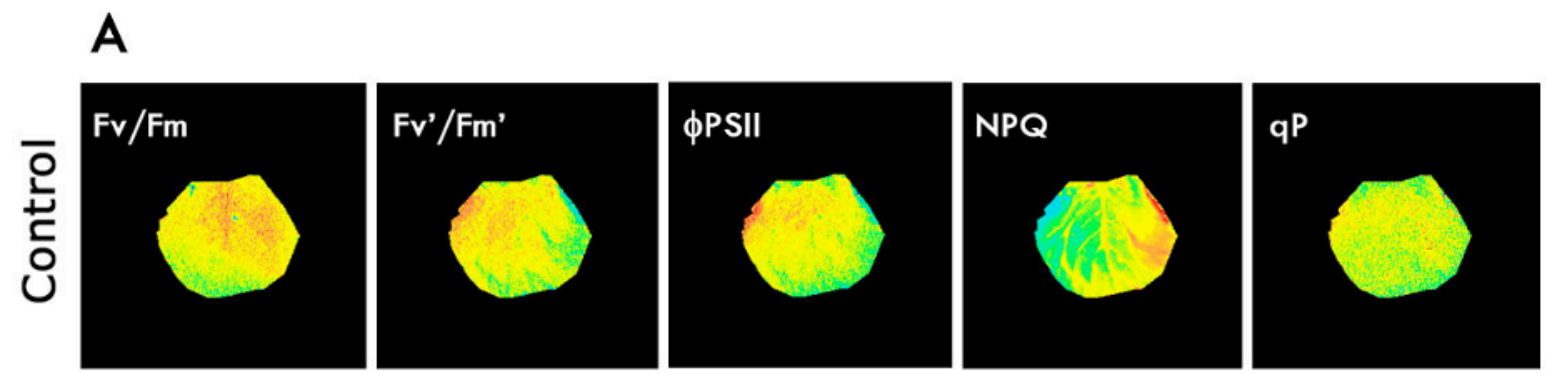

\section{於}
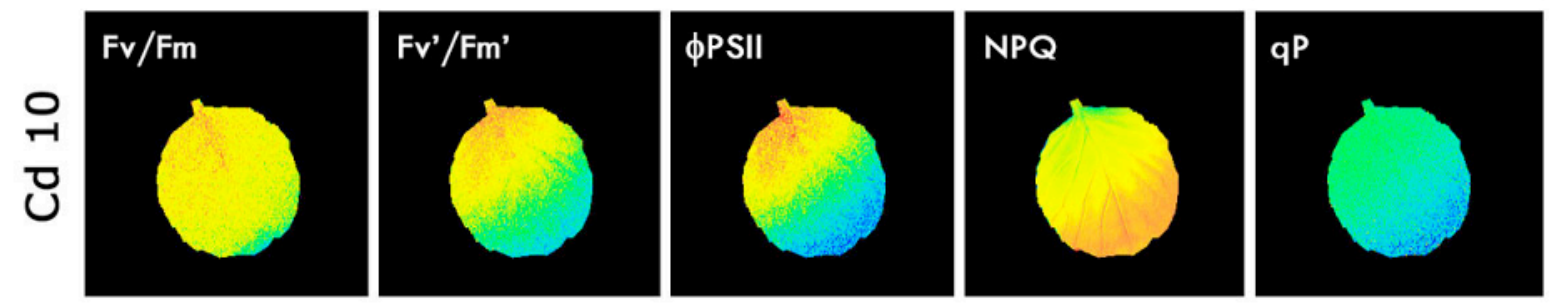

\section{B}
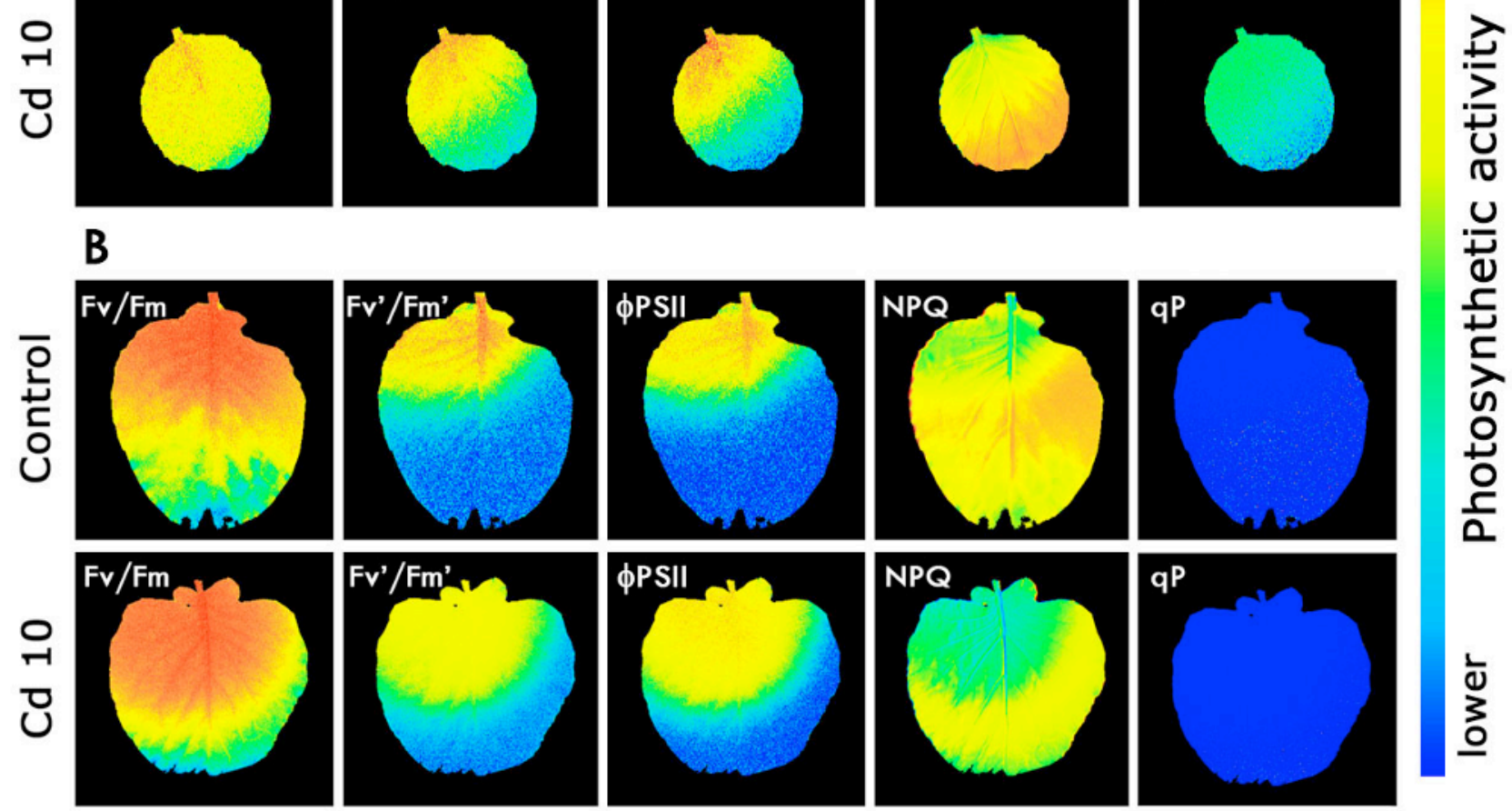

Fig. 2. Chl fluorescence images of Fv/Fm, Fv'/Fm', $\phi \mathrm{PSII}, \mathrm{NPQ}$ and qP in leaves of early ('DN'; A) and late ('AP'; B) cultivar of white cabbage. All images are representative for both control and cadmium-treated plants $(n=4)$.

Table 1. Summary of chlorophyll fluorescence parameters determined from fluorescence images of leaves of Cd- treated white cabbage plants similar to those shown in Fig. 2A, B. Mean \pm SD, $n=4$. The means labelled with the same letter are not significantly differentiated ( $\mathrm{P}<0.05$; paired Student's $t$-test).

\begin{tabular}{ccccccc}
\hline \multirow{2}{*}{ Cultivar } & \multirow{2}{*}{ Treatment } & \multicolumn{5}{c}{ Fluorescence parameters [mean \pm SD] } \\
\cline { 3 - 7 } & & $\mathrm{Fv} / \mathrm{Fm}$ & $\mathrm{Fv}^{\prime} / \mathrm{Fm}$ ' & $\phi$ PSII & $\mathrm{NPQ}$ & $\mathrm{qP}$ \\
\hline Early & Control & $0.797 \pm 0.007 \mathrm{a}$ & $0.504 \pm 0.055 \mathrm{a}$ & $0.426 \pm 0.043 \mathrm{a}$ & $1.537 \pm 0.062 \mathrm{a}$ & $0.846 \pm 0.016 \mathrm{a}$ \\
'DN' & Cd 10 & $0.781 \pm 0.008 \mathrm{~b}$ & $0.431 \pm 0.012 \mathrm{~b}$ & $0.325 \pm 0.011 \mathrm{~b}$ & $1.612 \pm 0.099 \mathrm{a}$ & $0.756 \pm 0.034 \mathrm{~b}$ \\
\hline Late & Control & $0.763 \pm 0.028 \mathrm{a}$ & $0.425 \pm 0.072 \mathrm{a}$ & $0.371 \pm 0.061 \mathrm{a}$ & $1.494 \pm 0.289 \mathrm{a}$ & $0.876 \pm 0.061 \mathrm{a}$ \\
'AP' & Cd 10 & $0.741 \pm 0.016 \mathrm{a}$ & $0.446 \pm 0.063 \mathrm{a}$ & $0.403 \pm 0.069 \mathrm{a}$ & $1.204 \pm 0.439 \mathrm{a}$ & $0.902 \pm 0.030 \mathrm{a}$ \\
\hline
\end{tabular}


Comparing the images of Chl fluorescence parameters, it was distinct that the distribution of photosynthetic activity was dependent on two factors: the cultivar and, among the cultivar, leaf section. Hence, numeric values, which are the averaged data collected from the whole leaf, cannot reveal the tissue specificity. The most photosynthetically active parts of the leaf were the areas located between the base (close to the petiole) and the center of the leaf blade. It can be important when measuring various processes on leaves and taking samples from them for further analyses.

\section{Conclusions}

The measurements of $\mathrm{Chl}$ content by greening index and assays of $\mathrm{Chl}$ fluorescence by imaging techniques can be applied in studies the efficiency of photosynthetic apparatus of HM-stressed plants. The most useful parameters of $\mathrm{Chl}$ fluorescence which can be helpful in assessing the level of cadmium stress in plants are $\mathrm{Fv} / \mathrm{Fm}, \mathrm{Fv}^{\prime} / \mathrm{Fm}^{\prime}, \phi_{\text {PSII }}$ and $\mathrm{qP}$, which allow to reveal the photosystem II (PSII) activity. Chl fluorescence imaging techniques also permit to observe the alterations in photosynthetic activity within the whole leaf.

\section{Acknowledgements}

Project The exploitation of white cabbage for phytoremediation and biofumigation of soils (AGROBIOKAP) co-financed by European Union from European Regional Development Fund in a framework of the Innovative Economy Operational Programme 2007-2013.

\section{References}

Antonkiewicz J., Jasiewicz Cz., Lošak T. Using Virginia fanpetals for extraction of heavy metals from soil. Acta Scientiarum Polonorum 2006; 5 (1): 63-73. (in Polish).

Bączek-Kwinta R., Bartoszek, A. Kusznierewicz B, Antonkiewicz J. Physiological response of plants and cadmium accumulation in heads of two cultivars of white cabbage. Journal of Elementology 2011a; 16: 355-364.

Bączek-Kwinta R., Kozieł A., Seidler-Łożykowska K. Are the fluorescence parameters of German chamomile leaves the first indicators of the anthodia field in drought conditions? Photosynthetica 2011b; 49 (1): 87-97.

Chen X., Wang J., Shi Y., Zhao M.Q., Chi G. Y. Effects of cadmium on growth and photosynthetic activities in pakchoi and mustard. Botanical studies 2011; 52: 41-46.

Das P., Samantaray S., Rout G..R. Studies on cadmium toxicity in plants: A review. Environmental Pollution 1997; 98: 29-36.

Haouari Ch. Ch., Nasraoui A. H., Bouthour D., Houda M. D., Daieb Ch. B., Mnai J., Gouia H. Response of tomato (Solanum lycopersicon) to cadmium toxicity: Growth, element uptake, chlorophyll content and photosynthetic rate. African Journal of Plant Science 2012; 6 (1): 1-7.

Hsu Y.T., Kao Ch.H. Cadmium toxicity is reduced by nitric oxide in rice leaves. Plant Growth Regulation 2004; 42: 227-238.

Lichtenehaler H.K., Babani F., Langsdorf G., Buschmann C. Measurement of differences in red chlorophyll fluorescence and photosynthetic activity between sun and shade leaves by fluorescence imaging. Photosynthetica 2000; 38(4): 521-529.

Lichtenehaler H.K., Miehè J.A. Fluorescence imaging as a diagnostic tool for plant stress. Trends in Plant Science 1997; 2(8): 316-320.

Maxwell K., Johnson G. N. Chlorophyll fluorescence a practical guide. Journal of Experimental Botany 2000; 51 (345): 659-668.

Murakami M., Ae N., Ishikawa S. Phytoextraction of cadmium by rice (Oryza sativa L.), soybean (Glycine max (L.) Merr.), and maize (Zea mays L.). Environmental Pollution 2007; 145:96-103.

Roháček K., Soukupová J., Barták M. Chlorophyll fluorescence: A wonderful tool to study plant physiology and plant stress. Plant Cell Compartments - Selected Topics 2008; 41-104.

Shafi Tantrey M., Agnihotri R. K. Chlorophyll and proline content of gram (Cicer arietinum L.) under cadmium and mercury treatments. Research Journal of Agricultural Sciences 2010; 1 (2): 119122.

Sofo A., Dichio B., Montanaro G., Xiloyannis C. Photosynthetic performance and light response of two olive cultivars under different water and light regimes. Photosynthetica 2009; 47: 602-608.

Wei S., Zhou Q., Saha U.K. Hyperaccumulative characteristics of weed species to heavy metals. Water, Air and Soil Pollution 2008; 192: 173-181. 